\title{
Women's experiences of sexuality after spinal cord injury: a UK perspective
}

\author{
Helen Thrussell ${ }^{1,2} \cdot$ Maureen Coggrave $^{3} \cdot$ Allison Graham $^{2} \cdot$ Angela Gall $^{4} \cdot$ Michelle Donald $^{2} \cdot$ Richa Kulshrestha $^{5}$. \\ Tracey Geddis ${ }^{2}$
}

Received: 22 October 2017 / Revised: 23 July 2018 / Accepted: 25 July 2018 / Published online: 23 August 2018

(C) International Spinal Cord Society 2018

\begin{abstract}
Study design Cross-sectional phenomenological qualitative study.

Objectives To investigate women's experience of sexuality after spinal cord injury (SCI) with a focus on rehabilitation and manging practical impact.

Setting Women with SCI living in the community in United Kingdom (UK).

Methods Participants were recruited via three UK SCI centres, ensuring tetraplegia, paraplegia and cauda equina syndrome representation. Single semi-structured interviews exploring individual's experiences around sexuality following SCI were recorded and transcribed for thematic analysis.

Results Twenty-seven women aged 21-72 years, sexually active since SCI were interviewed, each lasting 17-143 min (mean $55 \mathrm{~min}$ ). Six key themes emerged: physical change, psychological impact, dependency, relationships and partners, post injury sexual life and sexuality rehabilitation.

Conclusions Sexuality remains an important, valued aspect of female identity following SCI; sexual activity continues and though altered remains enjoyable and rewarding. Sexuality rehabilitation should commence early, preparing women for altered sexual sensation, disclosure of altered sexual function to partners, and encouraging early self-exploration. Techniques optimising continence management in preparation for and during sex should be taught. Participants identified a need for women-only education and support groups, increased peer support, self-esteem, communication and social skills training and even fashion advice and pampering sessions during rehabilitation. Support and education for partners are needed. Staff require support to be knowledgeable and confident in addressing women's sexuality needs. Use of the Ex-PLISSIT model for psychosexual support could help staff to better meet these needs.
\end{abstract}

Electronic supplementary material The online version of this article (https://doi.org/10.1038/s41393-018-0188-6) contains supplementary material, which is available to authorised users.

Helen Thrussell

helen.thrussell@nhs.net

1 Buckinghamshire New University, High Wycombe Campus, Queen Alexandra Road, High Wycombe HP11 2JZ, UK

2 National Spinal Injuries Centre, Stoke Mandeville Hospital, Mandeville Road, Aylesbury, Bucks HP21 8AL, UK

3 Florence Nightingale Faculty of Nursing, Midwifery and Palliative Care, King's College London, James Clerk Maxwell Building, 57 Waterloo Road, London SE1 8W, UK

4 London Spinal Cord Injury Centre, Royal National Orthopaedic Hospital, Brockley Hill, Stanmore HA7 4LP, UK

5 Midland Centre for Spinal Injuries, The Robert Jones \& Agnes Hunt Orthopaedic Hospital NHS Foundation Trust, Oswestry, Shropshire SY10 7A, UK

\section{Introduction}

Sexuality forms an integral part of individual identity [1], encompassing how individuals think, feel, identify and express themselves, and establish relationships [2]. Current literature on sexuality following spinal cord injury (SCI) and cauda equina syndrome (CES, included in SCI throughout this paper) focuses largely on males, with little exploration of women's needs [3], attributable to the larger proportion of males with traumatic SCI [4], the complexities of erectile dysfunction and male fertility [5] and potentially reflecting societal perceptions around sexuality in disabled individuals [6]. No qualitative studies with significant participant numbers have explored women's sexuality after SCI from a UK perspective.

Depending on the level and density of injury, female sexual function is affected directly and indirectly by SCI. 
Genital sensation, vaginal lubrication and orgasm may be impaired [7-9]; reduced mobility, incontinence, pain and spasticity are common [3, 10-12]. Psychosexual consequences may limit sexual activity and adjustment more than physical impairments [12, 13], particularly regarding desire, subjective arousal, body image, self-esteem and selfconfidence [12]. Relationships are also affected [12-14]; associations between stable relationships, sexual satisfaction and self-esteem have been identified [14, 15].

Women may not receive appropriate support around altered sexuality during rehabilitation [1, 12, 16]. Little research has explored women's priorities and needs regarding sexuality, including when after injury support for altered sexuality should be provided. It has been suggested that rehabilitation should encourage individuals' positive self-esteem and provide partner counselling, helping both parties adapt to life after a SCI [17], but it is unclear from the literature whether such recommendations are achieved in current clinical practice.

Most qualitative studies exploring sexuality in SCI women have small participant numbers and few have explored the perspective of women themselves in detail; none extensively explore the practical impact of SCI-related impairments on sexuality and their management. This study aimed to explore women's lived experience of sexuality and sexuality rehabilitation in the United Kingdom (UK), including how women manage SCI symptoms around sexual activity, to support improved female sexual rehabilitation outcomes by promoting research and practice development which addresses women's needs and priorities.

\section{Methods}

An applied phenomenological study was undertaken to obtain a descriptive, realist account of the lived experience of sexuality and sexual rehabilitation among women with SCI. An interpretive phenomenological approach seeks to ascertain and understand phenomena from the perspective of the individuals who experience it while acknowledging the contribution of both the context in which experiences occur, and the researchers own experience in the interpretation of the data. While an objective approach is essential, bracketing, or the setting aside of the researchers' experiences and perspective, is not undertaken [18]. This is appropriate in an applied qualitative study, where the research questions arose from the clinical practice of the researchers. The chief investigator was a nurse with more than 25 years of experience in SCI care and the interviewer an occupational therapist with 13 years of experience in SCI care. Two women with SCI were included in the research team. Data collection was undertaken using loosely structured interviews to explore the experiences and priorities of participants; a prompt list (appendix 1-data on menstrual issues will be reported in a separate publication) was utilised to ensure that issues identified from the literature and the experience of the researchers were addressed.

Purposive sampling was undertaken to recruit a sample of up to 30 women reflecting a range of ages, and the sample stratified to include varied levels and density of SCI. Recruitment was continued until data saturation was achieved, i.e., no new information was generated from interviews [19]. Consecutive volunteers, who met the inclusion criteria, were recruited from three SCI centres in the UK. These criteria were age 18 years or older, SCI of any level and density affecting sexual function, at least 1 year post-initial rehabilitation and sexually active since SCI. Sexual orientation was not an inclusion or exclusion criteria. Following their response to an invitation letter sent to all female patients, over 18 years, of participating centres, potential participants were contacted by telephone to assess whether inclusion criteria were met and to discuss participation in the study.

Participants were interviewed once by a single researcher in their home or SCI centre, or via tele-conferencing or telephone. Written informed consent was gained prior to interviews, which were digitally recorded and professionally transcribed. Access to a psychosexual therapist after interview was available for all participants, if required.

Nvivo software supported content analysis using a thematic approach consisting of coding of data, identification of concepts and themes, sorting of data by theme or concept and summarising or synthesising the data to produce descriptive and explanatory accounts [20]. Coding of data was undertaken by the researcher who interviewed the participants, and the chief investigator. Transcriptions were shared with other members of the research team to identify themes.

We certify that all applicable institutional and governmental regulations concerning the ethical use of human volunteers were followed during the course of this research. Two lay women with SCI contributed to the development and conduct of this study as part of the research team.

\section{Results}

A total of 937 invitations were sent to potential participants. Sixty-six women were contacted by telephone after responding positively to the invitation letter. Where volunteers did not meet inclusion criteria or the required number in that sample stratification were already met, this was explained and they were thanked for their interest. One woman was referred directly to a psychosexual therapist following the initial screening process. 
Table 1 Demographic and injury characteristics of participants

\begin{tabular}{|c|c|c|c|c|c|c|}
\hline Part. no. & Level of SCI & Cause of injury & Age at injury & Age at interview & Marital status at injury & Marital status at interview \\
\hline 1 & CES & Non-traumatic & 36 & 44 & Single & In relationship \\
\hline 2 & T5, AIS Grade D & Non-traumatic & 45 & 48 & Married & Single \\
\hline 3 & T4, AIS Grade C & Non-traumatic & 27 & 38 & Married & Married \\
\hline 4 & T11, AIS Grade D & Traumatic & 25 & 26 & Single & Dating \\
\hline 5 & T7, AIS Grade A & Traumatic & 31 & 37 & In relationship & Co-habiting ${ }^{\mathrm{a}}$ \\
\hline 6 & C5, AIS Grade D & Traumatic & 15 & 50 & In relationship & Married \\
\hline 7 & T10, AIS Grade A & Traumatic & 64 & 73 & In relationship & Married \\
\hline 8 & T12, AIS Grade C & Traumatic & 15 & 38 & Single & Married \\
\hline 9 & CES & Non-traumatic & 31 & 34 & Co-habiting & Co-habiting \\
\hline 10 & C6, AIS Grade B & Traumatic & 34 & 50 & In relationship & Married $^{\mathrm{a}}$ \\
\hline 11 & T4, AIS Grade A & Traumatic & 19 & 69 & In relationship & Married $^{\mathrm{a}}$ \\
\hline 12 & CES & Non-traumatic & 55 & 56 & Married & Married \\
\hline 13 & C5, AIS Grade C & Traumatic & 26 & 41 & Co-habiting & Co-habiting ${ }^{\mathrm{a}}$ \\
\hline 14 & CES & Traumatic & 43 & 51 & Civil partnership & Married \\
\hline 15 & CES & Traumatic & 42 & 52 & In relationship & Co-habiting \\
\hline 16 & CES & Non-traumatic & 34 & 59 & Married & Married \\
\hline 17 & C4, AIS Grade D & Traumatic & 50 & 52 & Single & Single \\
\hline 18 & T12, AIS Grade C & Traumatic & 37 & 42 & Co-habiting & In relationship ${ }^{a}$ \\
\hline 19 & T12, AIS Grade A & Non-traumatic & 49 & 60 & Married & Married \\
\hline 20 & T9, AIS Grade A & Traumatic & 41 & 61 & Married & Married \\
\hline 21 & C5, AIS Grade D & Non-traumatic & 44 & 45 & Married & Married \\
\hline 22 & L1, AIS Grade C & Non-traumatic & 68 & 72 & Married & Married \\
\hline 23 & CES & Non-traumatic & 19 & 21 & In relationship & In relationship ${ }^{a}$ \\
\hline 24 & C3, AIS Grade D & Non-traumatic & 58 & 69 & Married & Married \\
\hline 25 & T11, AIS Grade B & Non-traumatic & 30 & 45 & Married & Married \\
\hline 26 & C5, AIS Grade D & Traumatic & 57 & 59 & Co-habiting & Co-habiting \\
\hline 27 & C5, AIS Grade D & Traumatic & 26 & 36 & In relationship & In relationship ${ }^{\mathrm{a}}$ \\
\hline
\end{tabular}

CES Cauda Equina syndrome, Part. no. participant number

${ }^{a}$ Different partner to time of injury

Twenty-seven of 66 responders aged 21-72 years were interviewed (duration 17-143 min, mean $55 \mathrm{~min}$ ) before data saturation was achieved. Demographic and injury details of participants are given in Table 1 . Of 12 women with paraplegia recruited to the study, five had Asia Impairment Scale (AIS) A injuries, one B, two C and two D. Of the nine participants with tetraplegia, one had an AIS B injury, two C and six D. Six women with CES were recruited to the study. Neurological levels were taken from the most recent assessment in the medical record, with consent, using the International Standards for Neurological Classification of SCI. One woman was referred to psychosexual services after interview but not as a direct consequence of being interviewed. One woman was signposted on to fertility services and two others to peer support services.

Six interrelated themes emerged as summarised in Fig. 1. All participants contributed to the themes of physical

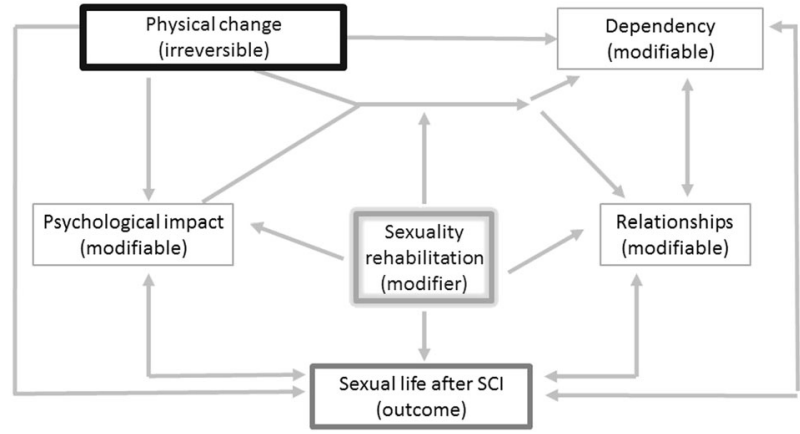

Fig. 1 Model of women's sexuality after SCI

change, psychological impact, sexual life after SIC and sexuality rehabilitation. All but two women contributed to the relationships and partners theme. Six women contributed to the dependency theme, three of whom were tetraplegic, two paraplegic and one diagnosed with CES. 


\section{Physical change}

Participants reported a range of physical consequences: reduced libido, arousal, satisfaction and orgasm; bladder, bowel and pelvic floor dysfunction; pain, spasticity and autonomic dysreflexia (AD). Altered vaginal sensation (absent, reduced, fluctuating or position dependent) was prevalent. While for some sensation improved over time, complete vaginal sensory loss was devastating and affected participants' view of intercourse:

"I told him to stop pretty soon after he penetrated me, because it was freaking me out that I couldn't feel it. Yes, so no it wasn't a good experience" (42 yrs, T12, C).

While enhanced erogenous zones above the SCI level (head, neck, back, lips, earlobes, nipples) were common and stimulation of these contributed to orgasm, other stimulation that was pleasurable pre-injury sometimes became hypersensitive and unpleasant. Some participants reported that medications including pregabalin, gabapentin and baclofen reduced their clitoral and vaginal sensation:

"If somebody said to me, you know, 'Your sexual dysfunction is down to the pregabalin,' I would never have believed it. But when you get off it, you think, 'Oh, okay, well it actually did make a big difference.'

It doesn't solve the problem but it does make a bit of a difference, yes" (38 yrs, T4, C).

Lack of vaginal lubrication was effectively managed with over-the-counter water-soluble gel. A degree of $\mathrm{AD}$ was tolerated during sex but severe occurrences meant stopping sexual activity. Urinary and faecal incontinence during sex was common, described as 'awful', 'embarrassing', 'mortifying', 'horrible', 'gross', 'distressing'. One participant ended a relationship after such an episode, while others reported partners seemed understanding and accepting of the risks:

"He's been messed on a few times, he's been wet more than a few times. Fortunately, he just kind of ignores it and we deal with it at the end. [...] I guess that's where being in an established relationship before the injury helps, because you already know each other. And if you're going to meet a new partner and then you go and mess all over them, that's, it's not the best start, is it?" (45 yrs, T11, B).
Though less frequent, inability to control stool or flatulence was considerably more difficult to endure than urinary leakage:

"This is really embarrassing, but when I'm having sex, it almost feels like I need to do a poo, like that's never happened before. And if I've got trapped wind, it will just come out without me being able to hold it in. There's no, I have no control over it when I'm having sex. [...]. But I just don't say anything, I just kind of ignore the fact that it's happened. It's like, 'oh my God, please don't say anything, don't notice that that just happened"" $(26$ yrs, T11, D)

Those with lower motor neurone injury found abdominal pressure from penetration expelled any stool in the rectum, intensified by certain positions (e.g., knees to abdomen). Digital rectal checking and evacuation of stool before sex, and avoidance of eating before sex was employed to reduce the risk of faecal incontinence. A regular bowel routine was also important and as bowel management skills improved with time from injury, participants found that the frequency of faecal incontinence reduced although the anxiety remained.

Strategies to reduce urinary leakage included catheterisation before sex and reduction of fluid intake in the hours before planned sexual activity. To reduce their risk of urinary tract infection (UTI), women washed and catheterised immediately after sex, impacting negatively on their experience. UTI was a sexual 'turn off' as was the use of incontinence sheets, catheters and urine bags:

"It is a killer and it's only because me and him are so close that we can kind of laugh it off. And he goes, 'If it doesn't bother you, it doesn't bother me.' But in the back of my mind, I tell him, 'Yes it does bother me a little bit, because it's not what I chose to have, is it? It's not something you'd stick on for sex" (41 yrs, C5, C).

The damaging impact of bladder and bowel dysfunction and management on sexuality and quality of life was clear:

"Our whole life revolves around bladder and bowel. So, yes, sexual activity is no differen"t (45 yrs, T11, B). 


\section{Psychological impact}

Anxieties were common: ability to satisfy a sexual partner, when sexual activity should recommence, risk of injury, what to expect, avoiding passivity. Relinquishing physical control to a partner was difficult but could be achieved:

"I hated the idea of feeling that I was being, not raped, but being used, you know, just lying there and - so, over time, we tried some other positions out. And it worked" (48 yrs, T5, D).

Satisfaction with body image was reduced. To look 'sexy' was difficult. Weight and shape changes, scarring and medical devices were difficult to accept:

"I certainly haven't accepted what I'm like. I don't like looking in the mirror, I don't like having photographs taken. I've gained a lot of weight" (38 yrs, T4, C).

Management of incontinence, even when effective, impaired sexuality. Preparation for sex could be a 'mood killer':

"Okay you feel like sex, let's get down to it. And then I'd be like, "Oh well hang on a minute because I've got to go and empty my bladder, I've got to go and make sure there's nothing in my bowel $[\ldots .$.$] okay it's$ gone now, don't feel like it any more" (38 yrs, T4, C).

Emptying the bladder before sex was seen as essential but:

"Self-catheterising made me feel completely sexless" (69 yrs, C3, D).

Some women experienced feelings of detachment, and expressed a need to hide from others, referring negatively to their body:

"Dead from the waist down" (42 yrs, T12, C) or "'I'm a wreck, I'm half a person" (60 yrs, T12, A).

"I just thought, 'I'm never going to have a boyfriend again. I am ugly and my body is different, I don't like it and I don't want to show it to anybody else.' That's it for me" (37 yrs, T7, A).
Confidence and self-esteem were reduced after SCI but the support of significant others could help with this. For one woman, serial one-off sexual encounters increased her confidence; others reported that with increasing time since injury confidence grew.

"The last three years I've slowly started to feel a little bit more confident, better in myself, able to face the world a little bit better. But before that I was an absolute recluse. I wouldn't really go out, I wouldn't socialise. I wouldn't have people visit. I was miserable company" (44 yrs, CES).

Some recognised the impact of their low self-esteem on others' perceptions of them and the need to address it before engaging in a relationship:

"When you're projecting that you don't feel good about yourself, into the world, then people treat you like you're more of a victim" (42 yrs, T12, C).

\section{Dependency}

Participants with tetraplegia experienced frustration and guilt at needing their partner to manage sexual activity:

"I feel a bit bad for him, because I - if it was under normal circumstances, the lady would get up and clean their self up, wouldn't she [...] But if he wants sex with me, he also has to clean up all the mess afterwards" (41 yrs, C5, C).

Knowing that carers might be aware of sexual activity was a barrier to sexual activity:

"It's hard, because there's carers in the house [...] knowing that somebody else might hear and be involved - and you can hear people walking down the corridor. And that makes, that makes it awkward" (36 yrs, C5, B).

The partner's role was delicately balanced. Partners could help with care needs but not perceive themselves as carers. Needs such as undressing produced confusion between partner and carer roles. 
"He'll go, 'Why did you tell them I was your carer?' And I'll say to him, 'Because you do care for me.' And he goes, 'But I'm not your carer, I do it because I love you" (41 yrs, C5, C).

Sometimes a caring attitude risked changing 'lovers' to carer and dependent.

"He's always got in his mind, I think, that he's looking after me. Which is lovely at one level, but [...] it's not ideal, in terms of an equal relationship and that's sad really I think" (72 yrs, L1, C).

\section{Relationships and partners}

Relationship status influenced women's experiences of sexuality after SCI. For most of those in a stable relationship at the time of injury, this eased the impact of and adjustments to altered sexuality, and reinforced the emotional significance of sex:

"I've always enjoyed sex and it had nothing to do with like the end result, having the orgasm. It was all about the closeness thing. It's all about - to me, a marriage is about being close" (38 yrs, T4, C).

Conversely, SCI contributed to some established relationships ending due to changes in lifestyle and leisure interests, different emerging priorities and difficulty with adjustment:

"The accident brought us closer together emotionally, but it also created a rift because it was so difficult to adjust. I think I'm better off now I'm with somebody who chose me for who I am now rather than somebody who chose me for who I was" (42 yrs, T12, C).

Those single or in casual relationships at time of injury worried about future relationships:

"Am I ever going to be able to have a husband because I mean, unless you have a husband who's in a wheelchair [...] it's very difficult to understand (50 yrs, C6, B).

Some had tried internet dating though this came with risks:
"I thought it was a bit creepy, wanting to know about it (her disability) and, yes, they'd been with other wheelchair users. And he was like, 'That's not going to put me off. I quite fancy that, somebody like that.' [...] I just ignore them and don't do it. [...] But I wonder whether there's some men [...] find the chair, disabled thing better because they like to be a little bit more controlling" (36 yrs, C5, B).

How and when to disclose intimate disability-related information to potential sexual partners was challenging:

"It's taken me a long time being with them before I would want to have sex and have them stay over. Longer than I would have been able-bodied, I think. [...] I have to trust them a lot more" (36 yrs, C5, B).

particularly when disabilities are not obvious:

"When do you tell somebody something like that? And it is quite heart-breaking when they kind of - you don't hear from them again once you've told them. So, you know, you've gone on lots of dates and then you kind of bring up the conversation. It's almost like telling somebody you've got an STI (sexually transmitted infection)" (44 yrs, CES).

Some women opted to be immediately and completely open with a new partner:

"It's like, 'No, I'm like this, so we need to do it like that, because, you know, I don't move this leg. [...]' So it's always plain. Black and white" (38 yrs, T12, C).

In contrast, some women never shared the extent of their disability, particularly regarding bladder, bowel and orgasm dysfunction. Others felt they educated their partner about their SCI, though the timing of this varied within a new relationship.

The acceptance and support of a partner made participants feel secure and loved but the women's altered sexuality caused difficulties for some partners. A woman's inability to orgasm could be construed as personal failure; some partners feared causing harm during sex:

"If we're having a good run of sex, and then I start bypassing or getting the sweats, then that's, that will put him off, because he's like, 'If you're going to be 
this ill afterwards, why do I want to do something that will make you ill?" (41 yrs, C5, C).

\section{Sexual life after SCI}

Some women had low expectations of sexuality after SCI:

"It was just that that was going to be part of my life that wasn't going to happen. And it's always been quite an important part of my life. So yes I was really devastated that this was it" (44 yrs, CES)

Others feared recommencing their sex life, likened by one woman to losing her virginity again, by another as 'a whole new ball game' (45 yrs, T11, B). Rarely, satisfaction achieved from sexual intercourse increased post injury; more commonly loss of orgasm reduced sexual enjoyment:

"Not being able to orgasm [...] I've finally accepted that I'm not going to really get much or any pleasure from sex. Actually, not even much, any. Like, even the thought of it is just, it seems just like such a big chore, and it seems so pointless (21 yrs, CES).

Participants reported using masturbation to investigate their post-injury body:

"Don't be afraid to touch yourself. Because how can you tell your husband where to touch you if you don't know yourself?" (59 yrs, CES).

However, it is not always a positive experience:

"I had a little kind of fiddle around to see what I could feel [...] I wanted to know what I could expect from, you know, what - and there was nothing, absolutely nothing. I was pretty devastated actually" (31 yrs, T7, A).

Sexual spontaneity was lost for some women, associated with minimising the risk of incontinence and in scheduling sex when energy, spasm and pain were optimal. Preparation for sex was a 'military procedure' (34 yrs, CES) removing 'romance', but not preparing was too risky. Sex toys and pornography enhanced sexual experiences for some women.
"I did buy myself a dildo to see how I would feel, to experiment, you know. And I found that I liked it [...] I'd see things on TV and I'd realised that I did have a sexual desire [...] I actually bought a sex tape [...] then I bought myself a dildo" (50 yrs, C6, B).

Partners were also reported to benefit:

"Vibrators definitely work for both of you. The only thing I would tell you is never ever, to anybody, never ever be afraid to experiment" (59 yrs, CES).

Reduced physical flexibility and controllimited sexual positions and sometimes caused accidents (falls, pulled muscles and fractured pelvis). Profiling beds and pillows were used by many participants to assist with positioning, balance and comfort but using them also reduced spontaneity.

The use of humour and good communication within their relationship was important for some participants. Acceptance and gratitude that some sexual life was still possible were also expressed.

"It's not the same [as] pre-injury. But it's still something. And, like I said, for me, something is still better than nothing. And I just make do" (48 yrs, T5, D).

Even when unable to orgasm, most of the participants valued sex as a positive, rewarding experience, with the emotional component often increasing in importance:

"It was always the two went together, the physical and the emotional. But now, it's an awful lot more emotional. It's a, it's a lot more of that side of it" (45 yrs, C5, D).

\section{Sexuality rehabilitation}

Experience of sexuality rehabilitation was varied; experience with printed literature and group sessions covering fertility were common while some women received no information; other women saw sexual rehabilitation as male orientated. A demand for female-orientated sexual rehabilitation was frequently voiced:

"What I found is, it is all centred around men, it's all centred on their dysfunction and obviously they can't 
get an erection and there's all these toys and gadgets and things for them to do to get the erection. And Viagra and all of that. But when it comes to women, it seems that, well okay you can have sex normally, if you've got a willing partner to have sex with. But there is nothing out there that says how to climax [...] it can't be just about men and their sexual dysfunction after a spinal cord injury. It has got to be sort of a joint thing, because women like to have sex as well" (38 yrs, T4, C).

Women felt their sexuality seemed unimportant to healthcare professionals (HCPs), particularly for individuals single at injury:

"By focusing on men with spinal cord injury, it's kind of saying that, well, you know, if you're man, you will get another partner. But if you're a woman, well you might not. And you're dealing with too much crap to have that weighing down on you. You really are" (37 yrs, T7, A).

Participants felt that HCPs lack knowledge, are too embarrassed to discuss sex and are unable to signpost them to sources of information and support. Women wanted HCPs to be knowledgeable and approachable about sexuality; in education about sexuality after SCI, they wanted less emphasis on reproduction and more focus on enjoyment and the emotional aspects of sex:

"I think sometimes they're uncomfortable about talking about things like that. They're sort of, 'Oh let's push it under the carpet,' sort of thing. People need to be a bit more open about things like that. [...] if you are open, sexuality is part of everyday life, it's about who you are and what you are" (60 yrs, T12, A).

Participants wanted reassurance or 'permission' from HCPs to recommence sexual activity, to ensure they were not putting themselves at risk, to know what to expect and what was 'normal' after their SCI.

"Being told that $[\ldots]$ you're not delicate - because, after you come out of hospital, you're treated with kid gloves and you don't know what is safe to do and what isn't safe to do" (45 yrs, T11, B).

Women's experiences suggested that staff were unaware of how early some women explore sexuality with a partner, achieved despite inpatient status; independent living facilities or single-occupancy rooms provided private opportunities:

"It wasn't like planned, [...], it was like stealing something, you know, because I was still in rehab, you know. And I had my own room obviously. So that was that" (48 yrs, T5, D).

However, lacking confidence and feeling sexually unattractive during rehabilitation was common; support and opportunities to improve self-confidence, self-esteem, body image and social skills were identified as essential:

"Just going socially and talking to people, how to approach that, that you're still - I don't know, [...] worthy of conversation, [...] the physical practicalities, talking to somebody in an environment where everybody else is standing up - would have been useful before you go home. [...] yes, social relationships as well as intimate relationships" (45 yrs, T11, B).

Psychosexual counselling and women-only education sessions experienced by some participants were reported as beneficial. Couples counselling and greater access to peer support were identified as potential ways to improve sexuality rehabilitation:

"I know it was something that was worrying [husband] at least as much as me, about whether we would ever have a sex life again, and it might well have been useful if there was somebody who was trained that we could have spoken to as a couple, at that time, I think" (72 yrs, L1, C).

Access to a specialist HCP at all stages post injury was also identified as valuable:

"Coming towards recovery and leaving (rehabilitation), you are thinking about it, and wondering is it going to be the same, is there going to be problems? Am I going to work properly? And, you know, that type of thing. So, I think to have somebody make the approach [...] saying, 'Look, we're here. If you'd like to discuss it with us any time before you leave, just tell us.' Or, 'After you get home, if you have any problems, you can contact us on these numbers, and talk about it.' I think that would definitely be a good idea" (59 yrs, C5, D). 
Sexuality emerged as a highly personal issue for these women and they felt it should be addressed accordingly in the rehabilitation process. Their requirement for support was fluid with needs and expectations of individuals changing over time. For some, sexuality was not a priority during rehabilitation and women regretted missing opportunities to learn about what later seemed important. Many women suggested changes to sexuality rehabilitation but appreciated that style and content would need to be flexible:

"It depends on individual situations. You don't want to offend people. You don't want to scare people, you know. I think maybe sometimes a one-on-one session might work as well, before doing the group thing, [...] because if I go ahead and say, 'Okay, why don't you introduce some sexy videos,' it might be offensive to some people [...] But I know that it would definitely help some people. Well it's better to have an idea of people's levels of sexuality before injury and their expectation after injury, before you can make these changes or introduce these things" (48 yrs, T5, D).

"There needs to be some new way which doesn't involve the words 'sexual health', or saying, (laughter) I don't know, a cup of tea and a cake. I don't know how you pitch it, but I think [...] it's such a massive part of everyone's life [...] Maybe it's not to everybody else, I don't know. But I think [...] we could really do with help on it [...] I've said more to you than I have done to my incredibly close friends, [...] You don't open up, so it's very difficult to share. So maybe just imparting more information to people, and explaining how different it is [...] some people would go, 'Oh, I don't want to talk about it,' and others would go, 'No, actually, I really do want to talk about it.' 'I need to know...' You need to be able to manage your expectation"s (45 yrs C5, D).

\section{Discussion}

Women remain sexual beings after spinal cord injury; the importance of sex in their pre-injury lives was strongly expressed along with regret and longing for what was lost. Loss of sexual sensation combined with impaired mobility, risk of incontinence during sexual activity and impact of interventions to prevent it, resulted in loss of the pre-injury sexual self with reduced confidence, self-esteem, body image and sexual pleasure and satisfaction. While many participants felt that an enjoyable and satisfying sexual life was possible after SCI, the nature of existing relationships was altered and new relationships were more difficult to establish. Participants identified that more female-focused rehabilitation has the potential to modify this narrative and improve outcomes as summarised in Fig. 1.

Loss of continence and management of incontinence had a profound impact both on sexual self-image and ability to enjoy sexual activity. As in other papers [15, 21], participants were anxious about their ability to be attractive to or to sexually please a partner and despite an increased emphasis on the emotional significance of sexuality, many women reported an overall reduction in sexual satisfaction, particularly linked to loss of orgasm, in contrast to previous work [12]. Reflecting other studies [22], physical selfexploration was beneficial to some women and built their confidence, but for others was traumatic.

Participants identified increased interaction with more knowledgeable HCPs, a broader approach to education which addresses ways of achieving a satisfying sexual life after injury, and therapeutic intervention (psychosexual counselling) during rehabilitation and beyond as ways of reducing the impact of SCI on relationships.

\section{Implications}

While the physical results of SCI (1) are irreversible, other factors identified by participants (psychological impact (2), relationships (4) and dependency (3)), which influence and are influenced by post-injury sexuality (5) can potentially be modified through a female-orientated approach to sexuality rehabilitation (6), again as identified by participants. Early acknowledgement by HCPs of lost or altered sexual sensation, and greater knowledge of and positive engagement with sexuality issues could support a dialogue about postinjury sexuality and prepare women for changes in their sexual lives. Sensitivity to the impact of continence management is essential and research to explore how the impact of continence management can be ameliorated is urgently required. While self-exploration can be suggested as part of 'permission giving' around sexuality during rehabilitation, such exploration can be traumatic and suitable help should be available to support women in this process.

Rehabilitation for women should be adapted to provide gender-specific educational groups and rehabilitative activities, and should be broad-based, specifically addressing not only altered physiology, but optimal continence management around sex and use of adjuncts such as pornography and sex toys, social and communication skills to support relationships and support for partners. Use of existing inpatient facilities could be re-imagined to promote the private environment required for sexual exploration during in-patient care. Use of the Ex-PLISSIT model [23] as a 
clinical and educational framework could support HCPs to meet women's sexuality rehabilitation needs. This model places the concept of 'permission' (to raise and discuss sexual issues) at its core and emphasises it at every stage of the framework. Use of the model could create a rehabilitation environment, involving the whole multidisciplinary team, where women are aware that they can raise or discuss sexuality issues without embarrassment to themselves or staff. This could normalise discussions around sexuality, opening communication and enabling women to voice anxieties or ask specific questions. HCPs need to be knowledgeable, comfortable to initiate discussion of sexuality and empowered to refer on where appropriate. An HCP role specialising in women's sexuality, available during rehabilitation and beyond, would provide a clearly identifiable service, accessible when individually appropriate.

\section{Limitations}

Study participants were recruited from three SCI units in the UK. While their experiences may not reflect those of women rehabilitated elsewhere, transferability of these findings is supported by the multicentre nature of recruitment to the study and achievement of data saturation in what was a relatively large sample. As in other studies of sexuality, women with complete tetraplegia did not volunteer to participate, possibly because they are less likely to be sexually active $[10,12]$, hence the findings may not reflect the experiences of this group of women. Participants were self-selected and women with positive sexual experiences may have been more motivated to participate.

\section{Conclusion}

This study explored the lived experience of sexuality and sexual rehabilitation after SCI among a group of women of varied ages and levels, densities and duration of SCI. These women reported that their sexuality was significantly impaired by SCI but that their perception of themselves as sexual beings remained an important and valued aspect of their identity. Most of the participants were positive regarding their present and future relationships and the overriding theme of the interviews was that sexual activity continued after injury and though altered, could still be enjoyable and rewarding. Few interventions were available to deal with the physical implications of SCI for sex after injury and though they could be effective to some extent, they could also have a further negative impact on sexual experiences. The perceived male focus of current rehabilitation offerings may mean that the needs of women with SCI around dealing with their altered sexuality were not met. The development of a female focus in rehabilitation using the framework of the Ex-PLISSIT model, education about altered sexuality which goes beyond fertility topics to promote an enjoyable sexual life, and the inclusion of partners in sexuality rehabilitation could improve this. Research is required to explore the benefits of these recommendations.

Acknowledgements This study was funded through a Stoke Mandeville - Masson Research Award, Stoke Mandeville Spinal Research Trust, Stoke Mandeville Hospital, UK and was hosted by Buckinghamshire New University, where MC was Senior Lecturer when funding was awarded.

Authors contributions HT (research associate) was responsible for designing the research protocol, recruitment of participants, data collection and analysis and writing up the study for publication. MC (chief investigator) was responsible for conceiving the research question, acquiring funding, designing the research protocol, data analysis and writing up the study for publication. AG was responsible for assisting in the design of the study, assisting in the data analysis and approving the write-up of the study. AG was responsible for assisting in the design of the study, recruitment at one research site, assisting in data analysis and approving the write-up of the study. MD was responsible for assisting in the design of the study, data analysis and approving the write-up of the study. RK was responsible for assisting in the design of the study, recruitment at one research site, assisting in data analysis and approving the write-up of the study. TG was responsible for assisting in the design of the study, assisting in data analysis and approving the write-up of the study.

\section{Compliance with ethical standards}

Conflict of interest The authors declare that they have no conflict of interest.

\section{References}

1. Parker MG, Yau MK. Sexuality, identity and women with spinal cord injury. Sex Disabil. 2012;30:15-27.

2. MacRae N. Fact sheet: sexuality and the role of occupational therapy. The American Occupational Therapy Association, Inc. 2013. https://www.aota.org/ /media/Corporate/Files/AboutOT/Professiona 1s/WhatIsOT/RDP/Facts/Sexuality

3. Kreuter M, Taft C, Siösteen A, Biering-Sørensen F. Women's sexual functioning and sex life after spinal cord injury. Spinal Cord. 2011;49:154-60.

4. Westgren N, Hulting C, Levi R, Seiger A, Westgren M. Sexuality in women with traumatic spinal cord injury. Acta Obstet Gynecol Scand. 1997;76:977-83.

5. Harrison J, Glass CA, Owens RG, Soni BM. Factors associated with sexual functioning in women following spinal cord injury. Paraplegia. 1995;33:687-92.

6. Lee S, Fenge L-A. Sexual well-being and physical disability. Br J Soc Work. 2016;46:2263-81.

7. Ferreiro-Velasco ME, Barca-Buyo A, de la Barrera SS, MontotoMarqués A, Vázquez XM, Rodríguez-Sotillo A. Sexual issues in a sample of women with spinal cord injury. Spinal Cord. 2005;43:51-55.

8. Forsythe E, Horsewell JE. Sexual rehabilitation of women with a spinal cord injury. Spinal Cord. 2006;44:234-41.

9. Rees PM, Fowler CJ, Maas CP. Sexual function in men and women with neurological disorders. Lancet. 2007;369:512-25. 
10. Jackson AB, Wadley V. A multicenter study of women's selfreported reproductive health after spinal cord injury. Arch Phys Med Rehabil. 1999;80:1420-8.

11. Anderson KD, Borisoff JF, Johnson RD, Stiens SA, Elliott SL. The impact of spinal cord injury on sexual function: concerns of the general population. Spinal Cord. 2007;45:328-37.

12. Kreuter M, Siösteen A, Biering-Sørensen F. Sexuality and sexual life in women with spinal cord injury: a controlled study. J Rehabil Med. 2008;40:61-69.

13. Lombardi G, Del Popolo G, Macchiarella A, Mencarini M, Celso M. Sexual rehabilitation in women with spinal cord injury: a critical review of the literature. Spinal Cord. 2010;48:842-9.

14. Taleporos G, McCabe MP. Physical disability and sexual esteem. Sex Disabil. 2001;19:131-48.

15. Otero-Villaverde S, Ferreiro-Velasco ME, Montoto-Marqués A, Salvador de la Barrera S, Arias-Pardo AI, Rodriguez-Sotillo A. Sexual satisfaction in women with spinal cord injuries. Spinal Cord. 2015;53:557-60.

16. Fritz HA, Dillaway H, Lysack CL. "Don't think paralysis takes away your womanhood": sexual intimacy after spinal cord injury. Am J Occup Ther. 2015;69:1-10.
17. Kreuter M. Spinal cord injury and partner relationships. Spinal Cord. 2000;38:2-6.

18. Nelms T. Phenomenological philosophy and research. In: De Chesney M, editor. Nursing research using phenomenology. 1st ed. New York: Springer Publishing Company; 2015. p. 6.

19. Saunders S, Sim J, Kingstone T, Baker S, Waterfield J, Bartlam B, et al. Saturation in qualitative research: exploring its conceptualisation and operationalization. Qual Quant. 2018; 52:1893-907.

20. Spencer L, Ritchie J, O'Connor W. Analysis: practices, principles and processes. In: Ritchie J, Lewis J, editors. Qualitative research practice: a guide for social science students and researchers. 1st ed. London: SAGE Publications; 2003. p. 212.

21. Cramp J, Connolly M, Cosby J, Ditor D. The impact of urinary incontinence on sexual function and sexual satisfaction in women with spinal cord. Sex Disabil. 2014;32:397-412.

22. Klebine PL, Lindsey LL, Rivera P. Sexuality for women with spinal cordinjury. SCI Psychosoc Process. 2005;18:27-31.

23. Davis S, Taylor B. From PLISSIT to Ex-PLISSIT. In: Davis S, editor. Rehabilitation: the use of theories and models in practice. 1st ed. Edinburgh: Churchill Livingstone; 2006. p. 101-29. 